\title{
Comparison of the pharmacodynamics of protamine zinc insulin and insulin degludec and validation of the continuous glucose monitoring system iPro2 in healthy cats
}

\author{
Salesov, Elena ; Zini, Eric ; Riederer, A ; Lutz, Thomas A ; Reusch, Claudia E
}

\begin{abstract}
With the aim to improve current therapeutic and monitoring options for diabetic cats, the present study compared pharmacodynamic parameters of protamine zinc insulin (PZI) and insulin degludec and validated the continuous glucose monitoring system (CGMS) iPro2 with Sof-sensor and Enlite-sensor focusing on the low glycemic range. Three doses $(0.1,0.2$ and $0.3 \mathrm{IU} / \mathrm{kg})$ of the two insulin preparations and the CGMS iPro2 with two different sensors were tested in six healthy cats. After each insulin administration, onset of action, time to glucose nadir and duration of action were calculated by measuring glucose concentrations with a portable blood glucose meter (PBGM). After sensor placement, paired PBGM and sensor glucose measurements were done and analytical and clinical accuracy were calculated according to the ISO 15197:2013 criteria. Onset of action, time to glucose nadir and glucose nadir were similar for both insulin formulations. Duration of action of insulin degludec was significantly longer than those of PZI at $0.1 \mathrm{IU} / \mathrm{kg}(\mathrm{P}=0.043)$ and $0.2 \mathrm{IU} / \mathrm{kg}(\mathrm{P}=0.043)$. Overall, $166 / 191(87 \%)$ Sof-sensor measurements and 106/121 (88\%) Enlite-sensor measurements met ISO criteria for analytical accuracy, and all sensor measurements fulfilled ISO criteria for clinical accuracy. Insulin degludec was well tolerated in healthy cats and showed longer duration of action than PZI. Further studies on the use of insulin degludec in diabetic cats might be recommended. Both sensors had good clinical accuracy, when used with the CGMS iPro2, but the analytical accuracy was below the minimum set by ISO 15197:2013.
\end{abstract}

DOI: https://doi.org/10.1016/j.rvsc.2018.01.019

Posted at the Zurich Open Repository and Archive, University of Zurich

ZORA URL: https://doi.org/10.5167/uzh-149511

Journal Article

Accepted Version

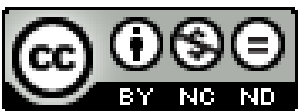

The following work is licensed under a Creative Commons: Attribution-NonCommercial-NoDerivatives 4.0 International (CC BY-NC-ND 4.0) License.

Originally published at:

Salesov, Elena; Zini, Eric; Riederer, A; Lutz, Thomas A; Reusch, Claudia E (2018). Comparison of the pharmacodynamics of protamine zinc insulin and insulin degludec and validation of the continuous glucose monitoring system iPro2 in healthy cats. Research in Veterinary Science, 118:79-85.

DOI: https://doi.org/10.1016/j.rvsc.2018.01.019 
1 Comparison of the pharmacodynamics of protamine zinc insulin and

2 insulin degludec and validation of the continuous glucose monitoring

3 system iPro2 in healthy cats

4

5 Elena Salesov ${ }^{1}$, Eric Zini ${ }^{1}$, Angelina Riederer ${ }^{1}$, Thomas A Lutz ${ }^{2}$, Claudia E

$6 \operatorname{Reusch}^{1}$

7

$8{ }^{1}$ Clinic for Small Animal Internal Medicine, Vetsuisse Faculty, University

9 of Zurich, Winterthurerstrasse 260, 8057 Zurich, Switzerland

$10{ }^{2}$ Institute of Veterinary Physiology, Vetsuisse Faculty, University of Zurich,

11 Winterthurerstrasse 260, 8057 Zurich, Switzerland

12

13

14 Corresponding author:

15 Elena Salesov, DVM

16 Clinic for Small Animal Internal Medicine, Vetsuisse Faculty, University of

17 Zurich, Winterthurerstrasse 260, 8057 Zurich, Switzerland; E-mail:

18 esalesov@vetclinics.uzh.ch 


\section{Abstract}

20 With the aim to improve current therapeutic and monitoring options for

21 diabetic cats, the present study compared pharmacodynamic parameters of

22 protamine zinc insulin (PZI) and insulin degludec and validated the

23 continuous glucose monitoring system (CGMS) iPro2 with Sof-sensor and

24 Enlite-sensor focusing on the low glycemic range.

25 Three doses $(0.1,0.2$ and $0.3 \mathrm{IU} / \mathrm{kg})$ of the two insulin preparations and the

26 CGMS iPro2 with two different sensors were tested in six healthy cats.

27 After each insulin administration, onset of action, time to glucose nadir and

28 duration of action were calculated by measuring glucose concentrations

29 with a portable blood glucose meter (PBGM). After sensor placement,

30 paired PBGM and sensor glucose measurements were done and analytical

31 and clinical accuracy were calculated according to the ISO 15197:2013

32 criteria.

33 Onset of action, time to glucose nadir and glucose nadir were similar for

34 both insulin formulations. Duration of action of insulin degludec was

35 significantly longer than those of PZI at $0.1 \mathrm{IU} / \mathrm{kg}(P=0.043)$ and $0.2 \mathrm{IU} / \mathrm{kg}$

$36(P=0.043)$. Overall, 166/191 (87\%) Sof-sensor measurements and 106/121

$37(88 \%)$ Enlite-sensor measurements met ISO criteria for analytical accuracy,

38 and all sensor measurements fulfilled ISO criteria for clinical accuracy.

39 Insulin degludec was well tolerated in healthy cats and showed longer

40 duration of action than PZI. Further studies on the use of insulin degludec in

41 diabetic cats might be recommended. Both sensors had good clinical 
42 accuracy, when used with the CGMS iPro2, but the analytical accuracy was

43 below the minimum set by ISO 15197:2013.

44 


\section{$45 \quad$ Keywords}

46 Protamine zinc insulin; insulin degludec; iPro2; Sof-sensor; Enlite-sensor;

47 continuous glucose monitoring system

48

49 Abbreviations

50 CGMS continuous glucose monitoring system

51 DM diabetes mellitus

52 ISO international organization for standardization

53 PBGM portable blood glucose meter

54 PZI protamine zinc insulin 


\section{1. Introduction}

56 Insulin is the cornerstone of treatment of cats with diabetes mellitus (DM).

57 Duration of insulin action was reported to be the most important factor, that

58 influences choice of insulin (Smith et al., 2012). A protamine zinc

59 preparation (PZI) for use in cats recently became available on the European

60 market. It is an intermediate to long-acting recombinant human insulin that

61 has been shown to be effective in diabetic cats (Nelson et al., 2009;

62 Norsworthy et al., 2009; Ward et al., 2015), but information about its

63 pharmacodynamics in cats is scarce. Insulin degludec is a new ultra-long

64 acting human insulin analogue. The formulation with a concentration of 100

$65 \mathrm{IU} / \mathrm{mL}$ is available on the market and could be used in diabetic cats.

66 Compared with insulin glargine, insulin degludec has a predictable and

67 stable glucose-lowering effect with fewer episodes of hypoglycemia in

68 human patients with type 1 or type 2 DM (Birkeland et al., 2011; Heller et

69 al., 2012; Rodbard et al., 2013). Moreover, when given three times a week,

70 insulin degludec provides glycemic control comparable to once-daily

71 treatment with insulin glargine (Zinman et al., 2011). To our knowledge,

72 there are no reports of the glucose-lowering effects of insulin degludec in

73 cats.

74 The generation of glucose curves is commonly used by veterinarians to

75 evaluate feline diabetic control (Smith et al., 2012). It helps in the

76 identification of hypoglycemia, and supports the decisions on treatment

77 adjustments. However, glucose curves have some limitations, even if the

78 glucose measurements are obtained in the cat's home environment. They do 
79 not provide continuous information about blood glucose concentrations, or

80 the glucose nadir and the glucose peak could be missed. In addition, the

81 duration of action of the insulin cannot be determined if home monitoring is

82 limited to a short period of time (i.e., $<12 \mathrm{~h}$ ). Another important limitation is

83 that not all owners are able to collect blood from their cats and generate

84 blood glucose curves.

85 Real-time continuous glucose monitoring systems (CGMS) continuously

86 measure the glucose concentration in the subcutaneous fat via a sensor

87 containing glucose oxidase and immediately display recorded values on a

88 monitor. These systems are considered useful for monitoring cats with DM

89 (Ristic et al., 2005; Moretti et al., 2010; Dietiker-Moretti et al., 2011; Gough

90 et. al., 2013; Hafner et al., 2013; Surman and Fleeman, 2013). However,

91 CGMSs are not suitable for home-monitoring because the maximum

92 distance between the cat and monitor should be only a few meters (Dietiker-

93 Moretti et al., 2011; Hafner et al., 2013). The CGMS iPro2 was designed to

94 measure and record glucose values in humans for up to 7 days without

95 displaying the data on a monitor; instead, at the end of the monitoring

96 period, the data are uploaded on a computer and evaluated retrospectively.

97 Because the iPro2 does not involve a monitor, it may be suitable for use in

98 diabetic cats in their home environment. Two different sensor types are

99 available, the enhanced Enlite-sensor and the Sof-sensor; the former is

100 shorter, more flexible and more accurate than the latter (Siegmund et al.,

101 2011). In human patients, the Enlite-sensor tends to measure glucose levels

102 lower than the reference over the entire glucose range, whereas the Sof- 
103 sensor measurements tend to be higher than reference values in the

104 hypoglycemic range and lower than reference values in the hyperglycemic

105 range (Calhoun et al., 2013). The use of the CGMS iPro2 and its reliability

106 using these two sensors have not been described in cats.

107 The aims of the study were to compare pharmacodynamic parameters of

108 PZI and insulin degludec in cats, including onset of action, time to glucose

109 nadir, glucose nadir and duration of action. Furthermore, ease of use,

110 tolerability, side effects, reliability, and the accuracy of CGMS iPro2 using

111 the two different sensors were evaluated. Particular attention was paid to the

112 accuracy of the iPro2 in the low glycemic range, because reliability of

113 measurements is crucial in hypoglycemic cats. 


\section{2. Materials and Methods}

\section{$115 \quad 2.1$ Animals}

116 Six healthy purpose-bred, neutered male, domestic shorthair cats were used.

117 The median age was 3.7 years (range $3.4-3.7$ ) and median body weight was

$1185.0 \mathrm{~kg}$ (range 4.7-5.9). All cats had body condition score of 5 on a 9-poin

119 scale. They were housed in groups of two, and were fed a commercial dry

120 food for adult cats twice daily. Food intake was adjusted to maintain a stable

121 body weight. During the $24 \mathrm{~h}$ before and after insulin administration, the

122 cats were individually kept in cages routinely used for hospitalized animals.

123 Food was withheld for $10 \mathrm{~h}$ before and $24 \mathrm{~h}$ after insulin injection. Cats had

124 free access to water. The study protocol was approved by the veterinary

125 office of the canton Zurich (permission number: 110/2014).

\section{$127 \quad 2.2$ Evaluation of two insulin preparations}

128 PZI 40 IU/mL (ProZinc, Boehringer Ingelheim, Basel, Switzerland) and

129 insulin degludec $100 \mathrm{IU} / \mathrm{mL}$ (Tresiba, Novo Nordisk Pharma, Küsnacht ZH,

130 Switzerland) were tested in a randomized crossover trial. Each cat received

$1310.1,0.2$ and $0.3 \mathrm{IU} / \mathrm{kg}$ of PZI and insulin degludec SC, respectively, two

132 weeks apart. Insulin syringes with 0.5 IU markings (Omnican 20, U-40

133 insulin, BBraun, Melsungen, Germany; BD MicroFine 0.3 ml, U-100

134 insulin, BD Medical, Le Pont de Claix, France) were used. The dose was

135 rounded up to the nearest half unit. Capillary blood glucose was measured at

136 the inner pinna of an ear with a portable blood glucose meter (PBGM)

137 AlphaTRAK2 (Abbott Animal Health, Baar, Switzerland) 30 and 5 minutes 
138 before and 30,60, 90, 120, 180, 240, 300 and 360 minutes after insulin

139 injection and then every $2 \mathrm{~h}$ for another $18 \mathrm{~h}$. Biochemical hypoglycemia

140 was defined as blood glucose $<3.6 \mathrm{mmol} / \mathrm{L}$.

141 If hypoglycemia caused vocalization, vomiting, tremors, or seizures, cats

142 received canned food with glucose syrup (Jubin ${ }^{\circledR}$, Andreas Jubin Pharma,

143 Bochum, Germany), or 50\% glucose solution $(0.5-1 \mathrm{~mL} / \mathrm{kg})$ was infused

144 intravenously. Hypoglycemia was not corrected, if only reduced physical

145 activity was observed.

146 Onset of insulin action, time to glucose nadir, and duration of insulin action

147 were calculated as described by Clark et al. (2012). The onset of insulin

148 action was defined as the interval between insulin administration and the

149 first glucose concentration that was at least 2 standard deviations lower than

150 baseline. The time to glucose nadir was defined as the interval between

151 insulin administration and the lowest measured glucose concentration. The

152 duration of insulin action was defined as the interval between the onset and

153 the end of insulin action, when measured glucose concentrations had

154 returned to within 2 standard deviations of baseline. The glucose data were

155 withdrawn from the calculation, if the insulin tests were terminated

156 (feeding, infusion of glucose solution), or if the onset of action could not be

157 achieved.

1592.3 Technical features of the CGMS iPro2 and the two sensors

160 The CGMS iPro2 (Medtronic, Münchenbuchsee, Switzerland) consists of a

161 digital recorder (Fig.1a) and a disposable sensor. The Sof-sensor 
162 (Medtronic, Münchenbuchsee, Switzerland) is $14.7 \mathrm{~mm}$ long and has a

163 volume of $3.6 \mathrm{~mm}^{3}$ (Fig. 1b). It is inserted through the skin into the

164 subcutaneous fat by means of a $17 \mathrm{~mm} 22 \mathrm{G}$ needle at an angle of $45-60^{\circ}$

165 and is fully hydrated within 10-15 minutes after positioning. The enhanced

166 Enlite-sensor (Medtronic, Münchenbuchsee, Switzerland) is $9.6 \mathrm{~mm}$ long

167 and has a volume of $0.2 \mathrm{~mm}^{3}$ (Fig. 1c). It is inserted by means of a $10.5 \mathrm{~mm}$

$16827 \mathrm{G}$ needle at a $90^{\circ}$ angle and is fully hydrated within 5 minutes after

169 positioning. Both sensors measure the interstitial glucose concentration in

170 the subcutaneous fat via an electrode that contains glucose oxidase (Hafner

171 et al., 2013). The iPro2 measures glucose concentrations between 2.2 and 22

$172 \mathrm{mmol} / \mathrm{L}$ every 5 minutes for up to 7 days. Data analysis is done using the

173 CareLink iPro software (Medtronic, Münchenbuchsee, Switzerland).

\section{$175 \quad 2.4$ Evaluation of CGMS with two sensors}

176 The cats were alternately implanted with a Sof-sensor or an Enlite-sensor 24

$177 \mathrm{~h}$ before the insulin injection. The insertion and removal of the sensors were

178 performed without sedation. Each sensor was placed in the subcutaneous

179 tissue of the neck area on the right side and secured with cyanoacrylate

180 adhesive (Cyanolit universal classic, 3M Consumer Healthcare, Rüschlikon,

181 Switzerland) as described previously (Hafner et al., 2013). The recorder was

182 connected to the sensor, initialized and then secured using a $3 \times 7 \mathrm{~cm}$ piece of

183 adhesive tape (Fig.1d). The video in the E-book chapter (Rand and Gottlieb,

184 2017) contains detailed information about placement of the glucose sensor

185 and iPro2-recorder. Calibrations were achieved by measuring capillary 
186 blood glucose concentrations 1 and $3 \mathrm{~h}$ after insertion of the sensor and then

187 every 8-12 h. Blood glucose concentrations were determined by use of the

188 PBGM AlphaTRAK2 previously evaluated for use in diabetic cats

189 (Cohenen et al., 2009; Zini et al., 2009). Each cat carried the sensor and the

190 recorder on it for seven days. Thereafter, they were gently removed from the

191 skin, and the glucose curve was downloaded. Ease of use of the sensors,

192 tolerability, reliability of the measurements and side effects were recorded.

\section{$194 \quad 2.5$ Statistical analysis}

195 Results are reported as median and range or as percentage, as appropriate.

196 Differences in pharmacodynamic parameters (onset of insulin action, time

197 to glucose nadir, glucose nadir and duration of insulin action) between the

198 same doses of two insulin preparations were analyzed using the Wilcoxon

199 matched pairs signet rank test. The Friedman test was used to compare three

200 different doses of one insulin formulation. Analytical and clinical accuracy

201 of the sensors was calculated conforming to the international organization

202 for standardization (ISO) 15197:2013 using Bland and Altman diagrams

203 and consensus error grid coordinates, respectively (Bland and Altman,

204 1986; Clarke et al., 1987). Accordingly, to be considered accurate, at least

$20595 \%$ of glucose readings had to fall within $\pm 0.83 \mathrm{mmol} / \mathrm{L}$ of those

206 measured with the reference method for concentrations $<5.5 \mathrm{mmol} / \mathrm{L}$ or

207 within $\pm 15 \%$ for concentrations $\geq 5.5 \mathrm{mmol} / \mathrm{L}$, and at least $99 \%$ of readings

208 had to be in zones A and B of the consensus error grid. To address the

209 clinical importance of hypoglycemia, glucose curves with concentrations 
210 predominantly $<3.6 \mathrm{mmol} / \mathrm{L}$ were chosen for analysis. Paired glucose

211 readings from the PBGM and the two sensors were divided into a group

212 with $\mathrm{PBGM}$ readings $<5.5 \mathrm{mmol} / \mathrm{L}$ and a group with $\mathrm{PBGM}$ readings $\geq 5.5$

$213 \mathrm{mmol} / \mathrm{L}$. Additionally, Spearman correlation coefficients (rho) were

214 calculated for paired glucose readings. Differences were considered

215 significant at $P<0.05$. A commercial software (GraphPad PRISM 6,

216 GraphPad Software, La Jolla, USA) was used for analysis. 


\section{3. Results}

\section{$218 \quad 3.1$ Evaluation of PZI and insulin degludec}

219 Protamine zinc insulin and insulin degludec were well tolerated by all cats

220 and there were no injection site reactions. If the glucose lowering effect

221 could be achieved, all three doses of both insulin formulations caused

222 transient mild weakness, that was associated with biochemical

223 hypoglycemia and resolved without treatment within 1-3 $\mathrm{h}$ in all cats. The

224 onset of insulin action could not be achieved in three different cats treated

225 with $0.1 \mathrm{IU} / \mathrm{kg}$ of PZI (one cat), $0.1 \mathrm{IU} / \mathrm{kg}$ of insulin degludec (one cat), and

$2260.2 \mathrm{IU} / \mathrm{kg}$ of PZI (one cat). At the highest dose (0.3 IU/ $\mathrm{kg}$ ), PZI caused

227 hypoglycemia, and vomiting in 3/6 (50\%) cats; one of these cats had the

228 same reaction after $0.3 \mathrm{IU} / \mathrm{kg}$ of insulin degludec. The hypoglycemia was

229 corrected by feeding in three cats, and the glucose data were withdrawn

230 from the calculation. One cat treated with $0.3 \mathrm{IU} / \mathrm{kg}$ of PZI quickly

231 recovered without any interventions.

232 Medians and ranges of pharmacodynamic parameters of both insulin

233 formulations are shown in Table 1. Blood glucose curves are presented in

234 Fig. 2 (a-f). Equal doses of PZI and insulin degludec did not differ with

235 respect to glucose nadir, onset of action, and time to glucose nadir. Median

236 duration of action was significantly shorter for $0.1 \mathrm{IU} / \mathrm{kg}$ of PZI (7 h; range

237 1.5-7) than for $0.1 \mathrm{IU} / \mathrm{kg}$ of insulin degludec (11 h; range 9-22.5) $(P=0.043)$

238 and for $0.2 \mathrm{IU} / \mathrm{kg}$ of PZI (6.8 h; range 4.5-10.5) than for $0.2 \mathrm{IU} / \mathrm{kg}$ of insulin

239 degludec (12.5 h; range 8.0-20.0) $(P=0.043)$. However, there were no 
240 significant differences in the duration of action between two insulin

241 formulations at $0.3 \mathrm{IU} / \mathrm{kg}$.

242 The duration of action of PZI never reached $12 \mathrm{~h}$, while that of insulin

243 degludec was $\geq 12 \mathrm{~h}$ in two cats with $0.1 \mathrm{IU} / \mathrm{kg}$ and in three cats with 0.2 and

$2440.3 \mathrm{IU} / \mathrm{kg}$ (data not shown). Glucose nadir, onset of insulin action, time to

245 glucose nadir, and duration of insulin action of PZI and insulin degludec

246 were similar between different doses of each insulin formulations.

\section{$248 \quad 3.2$ Evaluation of CGMS with the Sof-sensor and Enlite-sensor}

249 The use of a total of 36 sensors (18 Sof and 18 Enlite) was scheduled.

250 However, we used 48 sensors (24 Sof and 24 Enlite), because some sensors

251 had to be replaced. Twenty of twenty-four (83\%) Sof-sensors and 17/24

252 (71\%) Enlite-sensors were properly placed and initialized. The remaining 11

253 sensors failed because of faulty manufacturing (1 Sof and 2 Enlite) or lack

254 of initialization (3 Sof and 4 Enlite). One Enlite-sensor was bent during

255 insertion. Both sensor types were easy to place and well tolerated by all

256 cats. Abnormal behavior related to the sensors did not occur. All cats had

257 mild local erythema after sensor removal, which resolved spontaneously

258 within $12-24 \mathrm{~h}$. One cat had a small dry scratch wound in the skin at the

259 caudal border of the Sof-sensor and another cat had a similar wound at the

260 caudal border of the Enlite-sensor. Both healed without treatment within 7-

$261 \quad 10$ days after sensor removal.

262 Glucose concentrations were recorded by all 20 properly placed and

263 initialized Sof-sensors and by 13/17 (76\%) Enlite-sensors. Four (24\%) 
264 Enlite-sensors failed to record glucose concentration, because the recorder

265 malfunctioned (two cats), the cat removed the sensor $1 \mathrm{~h}$ after insertion or

266 for unknown reasons (one cat). Seventeen of the twenty (85\%) functioning

267 Sof-sensors and 6/13 (46\%) functioning Enlite-sensors recorded the glucose

268 concentration during the entire 7-day study period. The remaining $3 / 20$

269 (15\%) functioning Sof-sensors and 3/13 (23\%) Enlite-sensors recorded

270 glucose concentrations during at least $50 \%$ of the study period. The four

271 (31\%) other functioning Enlite-sensors recorded glucose concentration

272 during $<50 \%$ of the study period.

273 Uninterrupted recording of glucose concentrations occurred in 8/20 (40\%)

274 functioning Sof-sensors and in 8/13 (66\%) functioning Enlite-sensors.

275 Overall, there were 27 and 23 interruptions with the Sof-sensor and the

276 Enlite-sensor, respectively. Twenty-three of the twenty-seven (85\%)

277 interruptions that occurred with the Sof-sensor and 16/23 (70\%) that

278 occurred with the Enlite-sensor lasted $<1 \mathrm{~h}$. The remaining four $(15 \%)$

279 interruptions with the Sof-sensor and seven (30\%) with the Enlite-sensor

280 lasted between 1 and $24 \mathrm{~h}$.

281 A total of 191 paired PBGM-Sof-sensor and 121 paired PBGM-Enlite-

282 sensor glucose measurements were analyzed. One hundred and seventy-

283 seven of one hundred and ninety-one (93\%) Sof-sensor measurements and

284 113/121 (93\%) Enlite-sensor measurements were between 2.2 and 5.5

$285 \mathrm{mmol} / \mathrm{L}$. The remaining measurements were equal to $5.5 \mathrm{mmol} / \mathrm{L}$ or in the

286 range between 5.5 and $22 \mathrm{mmol} / \mathrm{L}$. The differences between glucose

287 measurements from the PBGM and the two CGMS iPro2 sensors are shown 
288 in Fig. 3. Considering the paired glucose measurements $<5.5 \mathrm{mmol} / \mathrm{L}$, $289160 / 177$ (90\%) Sof-sensor measurements and 102/113 (90\%) Enlite-sensor 290 measurements were within $\pm 0.83 \mathrm{mmol} / \mathrm{L}$ of the reference method and met

291 the ISO accuracy criteria. Of the paired glucose readings $\geq 5.5 \mathrm{mmol} / \mathrm{L}, 6 / 14$ 292 (43\%) of Sof-sensor measurements and 4/8 (50\%) Enlite-sensor

293 measurements were within $\pm 15 \%$ of the reference method and met the ISO

294 accuracy criteria. Overall, 166/191 (87\%) Sof-sensor measurements and $295106 / 121(88 \%)$ Enlite-sensor measurements met the ISO criteria for 296 analytical accuracy. All glucose concentrations measured with both sensors

297 were in zone A or B of the consensus error grid coordinates and met the ISO

298 criteria for clinical accuracy (Fig. 4). There were moderate positive

299 correlations between paired measurements from the PBGM and the Sof-

300 sensor (rho $=0.67, P<0.0001)$ and between paired measurements from the

301 PBGM and the Enlite-sensor (rho=0.69, $P<0.0001$ ). 


\section{4. Discussion}

303 This study compared pharmacodynamics of PZI and insulin degludec in

304 healthy cats. Marked biochemical hypoglycemia and weakness occurred

305 with both insulin formulations in all tests, when the glucose lowering effect

306 was achieved. Vomiting was limited to three cats receiving the highest dose

307 of PZI and to one cat receiving the highest dose of insulin degludec.

308 Both types of insulin had a similar onset of action, time to glucose nadir and

309 glucose nadir. Median duration of action was significantly longer for insulin

310 degludec than for PZI at 0.1 and $0.2 \mathrm{IU} / \mathrm{kg}$. The differences between two

311 insulins at $0.3 \mathrm{IU} / \mathrm{kg}$ was not significant. However, the duration of action

312 was about 1.5 times as long for insulin degludec than for PZI at all dose

313 levels. The duration of action of PZI was shorter than $12 \mathrm{~h}$ in all cats

314 irrespective of the doses. This differed from results of a recent study, in

315 which PZI had a duration of action exceeding $12 \mathrm{~h}$ in some of the treated

316 diabetic cats, and was therefore considered potentially useful for once-a-day

317 treatment (Ward and Louviere, 2015). Longer duration of action of PZI in

318 the mentioned study could be explained by the applied insulin dose $(0.5$

319 IU/kg or higher). In our study, higher insulin dose was not associated with

320 longer duration of action most likely due to rebound effect from

321 hypoglycemia. In contrast to PZI, duration of action of insulin degludec was

$322 \geq 12 \mathrm{~h}$ in the most cats irrespective of the doses. These preliminary data

323 justify a study on the use of insulin degludec as once-a-day treatment in

324 diabetic cats. 
325 Another objective of this study was to evaluate the CGSM iPro2 with the

326 Sof-sensor and the Enlite-sensor. From a technical standpoint, the process of

327 initialization of the iPro2, its calibration, and the range of glucose

328 concentrations measured were similar to the real-time CGMS previously

329 validated by our group (Moretti et al., 2009; Moretti et al., 2010; Hafner et

330 al., 2013). Sensor insertion was straightforward, and the implanted sensor

331 did not adversely affect cat's well-being. A unique feature of the CGSM

332 iPro2 is that it allows for continuous glucose monitoring in cats in a home

333 setting, which is a considerable advantage over the currently used real-time

334 CGMSs that require the presence of a digital recorder in close proximity to

335 the sensor. Therefore, the use of iPro2 might be recommended for cats with

336 poor controlled DM, or if stress-induced hyperglycemia, rebound

337 hyperglycemia, or large glycemic variability are suspected.

338 The Sof-sensor was more reliable with regard to the initial glucose readings;

339 all 20 placed Sof-sensors but only 13/17 Enlite-sensors successfully

340 initiated glucose measurements after placement. Moreover, 17/20 Sof-

341 sensors but only 6/13 Enlite-sensors recorded glucose data during the entire

342 7-day study period. Of note, 4/13 Enlite-sensors recorded glucose data

$343<50 \%$ of the study period. Despite the overall superior performance of the

344 Sof-sensor, the Enlite-sensors had numerically fewer interruptions of $<1 \mathrm{~h}$

345 in glucose recording than the Sof-sensors; however, we considered

346 occasional short interruptions in glucose recording of minor importance

347 from a clinical standpoint, because they do not affect the interpretation of

348 glucose curves in a significant way. Interruptions in glucose measurements 
349 may occur with either sensor if they are not properly hydrated or regularly

350 calibrated. Even slight changes in the position of the sensor caused by strain

351 on the recorder or the overlying skin can temporarily interrupt

352 measurements. The Enlite-sensor is thinner and shorter than the Sof-sensor

353 and therefore might be more susceptible to interruptions. Taken together,

354 our results suggest that the Sof-sensor is better suited to generate glucose

355 curves in cats than the Enlite-sensor.

356 Both sensors yielded similar and relatively good analytical accuracy based

357 on correlation analysis but did not completely fulfil the ISO criteria. In fact,

358 at glucose concentrations $<5.5 \mathrm{mmol} / \mathrm{L}$, both sensors had an analytical

359 accuracy of $90 \%$, which is below the required $95 \%$, and at glucose

360 concentrations $\geq 5.5 \mathrm{mmol} / \mathrm{L}$, the analytical accuracy of the Sof-sensor and

361 Enlite-sensor was $43 \%$ and 50\%, respectively, both considerably lower than

362 the required $95 \%$ accuracy. However, the present study involved healthy

363 cats and focused on hypoglycemia and thus the number of glucose readings

$364 \geq 5.5 \mathrm{mmol} / \mathrm{L}$ was low. Including diabetic cats in future studies will aid in

365 evaluation of the analytical accuracy of these sensors for glucose readings

$366 \geq 5.5 \mathrm{mmol} / \mathrm{L}$.

367 Clinical accuracy was evaluated by error grid analysis and was $100 \%$ for

368 both sensors in the hypo- and normoglycemic ranges. According to ISO

369 criteria, good clinical accuracy is achieved when at least $99 \%$ of glucose

370 measurements fall within zones $\mathrm{A}$ and $\mathrm{B}$ of the consensus error grid

371 coordinates, which occurred with both sensors in all cats. 
372 The study has some limitations. First, it was performed in a small number of

373 healthy young cats, and it might not reflect the effect of tested insulin

374 formulations in older diabetic cats. Sensor glucose readings are affected by

375 the hydration status of the subcutaneous fat, and it might be possible, that

376 the reliability and accuracy of the Sof-sensor and the Enlite-sensor are

377 adversely affected in older diabetic cats with compromised hydration.

378 Second, the method used in the study to assess pharmacodynamic

379 parameters of two insulin formulations is inferior to a isoglycemic clump

380 method, which has been considered as a gold standard for the study of

381 pharmacodynamics of insulin in people (Heise and Pieber, 2007; Gilor et

382 al., 2010). Traditional blood glucose curves display the effects of exogenous

383 insulin, endogenous insulin, glucagon, and stress hormones. Following

384 severe hypoglycemia, a return of glucose to baseline reflects not only the

385 diminishing effect of exogenous insulin, but could also be the result of

386 activation of glucagon and stress hormones. In few cases (both insulin

387 formulations, data not shown), we recognized a return of glucose

388 concentration to baseline followed by another decline to a smaller degree as

389 before. These could represent counter-regulatory response that masks the

390 effect of exogenous insulin. However, it could also represent physiological

391 glucose fluctuations. It is possible, that pharmacodynamic parameters of

392 both insulin formulations were underestimated due to activation of glucagon

393 and stress hormones. However, we assume, that the counter-regulatory

394 response in cats was similar with both insulin formulations, and

395 pharmacodynamic parameters could be easily compared. Third, we used 
396 insulin syringes to inject small amounts of insulin (0.5 - 1.5 IU). Insulin

397 syringes are known to be inaccurate and imprecise at doses lower than 5 IU

398 (Keith et al., 2004).

399 Fourth, the blood glucose was measured with PBGM and not with a routine

400 chemistry analyzer. However, the PBGM AlphaTRAK is specially designed

401 for use in pets. It was evaluated by different research groups, and was

402 shown to be precise and accurate at low, normal and high glucose levels;

403 glucose concentrations measured by AlphaTRAK did not significantly

404 deviate from the reference method (Cohen et al., 2009; Zini et al., 2009). 


\section{5. Conclusions}

406 Pritamine zinc insulin and insulin degludec are well tolerated by healthy

407 cats and cause similar degrees of hypoglycemia. Insulin degludec showed

408 longer duration of action than PZI. Further studies on the use of insulin

409 degludec in diabetic cats might be recommended. The CGMS iPro2 with the

410 Sof-sensor or the Enlite-sensor is well tolerated by healthy cats. Both

411 sensors provide good clinical accuracy but analytical accuracy does not

412 reach the minimum set by ISO 15197:2013. The Sof-sensor seems more

413 suitable for use in cats than the Enlite-sensor, because it produces initial

414 glucose readings more reliably and has a better potential to generate glucose

415 curves. However, pharmacodynamics of insulin degludec, and CGMS iPro2

416 need to be investigated in a larger population of diabetic cats.

\section{$418 \quad$ Funding}

419 This research did not receive any specific grant from funding agencies in the

420 public, commercial, or not-for-profit sectors.

\section{Conflict of interest}

423 Claudia Reusch has a consultancy agreement with Boehringer Ingelheim

424 Vetmedica GmbH. 


\section{References}

426 1. Birkeland, K.I., Home, P.D., Wendisch, U., Ratner, R.E., Johansen,

427 T., Endahl, L.A., Lyby, K., Jendle, J.H., Roberts, A.P., DeVries,

428 J.H., Meneghini, L.F., 2011. Insulin degludec in type 1 diabetes: a

429 randomized controlled trial of a new-generation ultra-long-acting

$430 \quad$ insulin compared with insulin glargine. Diabetes care. 34, 661-665.

431 2. Bland, J.M., Altman, D.G., 1986. Statistical methods for assessing

432 agreement between two methods of clinical measurement. Lancet. 1,

$433 \quad 307-310$.

434 3. Calhoun, P., Lum, J., Beck, R.W., Kollman, C., 2013. Performance

435 comparison of the Medtronic Sof-sensor and Enlite glucose sensors

436 in inpatient studies of individuals with type 1 diabetes. Diabetes

437 Technol Ther. 15(9), 758-761.

438 4. Clark, M., Thomaseth, K., Heit, M., Hoenig, M., 2012.

439 Pharmacokinetics and pharmacodynamics of protamine zinc

440 recombinant human insulin in healthy dogs. J Vet Pharmacol Ther.

$441 \quad 35,342-250$.

442 5. Clarke, W.L., Cox, D., Gonder-Frederick, L.A., Carter, W., Pohl,

443 S.L., 1987. Evaluating clinical accuracy of systems for self-

444 monitoring of blood glucose. Diabetes care. 10, 622-628.

445 6. Cohen T.A., Nelson R.W., Kass P.H., Christopher M.M., Feldman

446 E.C., 2009. Evaluation of six portable blood glucose meters for

447 measuring blood glucose concentration in dogs. JAVMA. 235(3),

$448 \quad 276-280$. 
449

450

451

452

453
7. Dietiker-Moretti, S., Muller, C., Sieber-Ruckstuhl, N., Tschour, F., Osto, M., Franchini, M., Ackermann, M., Lutz, T.A., Reusch, C.E., Zini, E., 2011. Comparison of a continuous glucose monitoring system with a portable blood glucose meter to determine insulin dose in cats with diabetes mellitus. J Vet Intern Med. 25, 1084-1088.

8. Gilor, C., Ridge, T.K., Attermeier, K.J., Graves, T.K., 2010. Pharmacodynamics of insulin detemir and insulin glargine assessed by an isoglycemic clamp method in healthy cats. J Vet Intern Med. $24,870-874$.

9. Gough, S.C., Bhargava, A., Jain, R., Mersebach, H., Rasmussen, S., Bergenstal, R.M., 2013. Low-volume insulin degludec 200 units/mL once daily improves glycemic control similar to insulin glargine with a low risk of hypoglycemia in insulin-naive patients with type 2 diabetes. Diabetes care. 36(9), 2536-2542.

10. Hafner, M., Lutz, T.A., Reusch, C.E., Zini, E., 2013. Evaluation of sensor sites for continuous glucose monitoring in cats with diabetes mellitus. J Feline Med Surg. 15, 117-123.

11. Heise, T., Pieber T.R., 2007. Towards peakless, reproducible and long-acting insulins. An assessment of the basal analogues based on isoglycemic clump studies. Diabetes Obes Metab. 9, 648-659

12. Heller, S., Buse, J., Fisher, M., Garg, S., Marre, M., Merker, L., Renard, E., Russel-Jones, D., Philotheou, A., Francisco, A.M., Pei, H., Bode, B., BEGIN Basal-Bolus Type 1 trial investigators, 2012. Insulin degludec, an ultra-longacting basal insulin, versus insulin 
glargine in basal-bolus treatment with mealtime insulin aspart in type 1 diabetes (BEGIN Basal-Bolus Type 1): a phase 3, randomised, open-label, treat-to-target non-inferiority trial. Lancet. 379, 1489-1497.

13. Keith, K., Nicholson, D., Rogers, D., 2004. Accuracy and precision of low-dose insulin administration using syringes, pen injectors and a pump. Clin Pediatr. 43(1), 69-74.

14. Moretti, S., Tschuor, F., Osto, M., Franchini, M., Ackermann, M., Lutz, T.A., Reusch, C.E., Zini, E., 2010. Evaluation of a novel realtime continuous glucose-monitoring system for use in cats. J Vet Intern Med. 24, 120-126.

15. Moretti, S., Zini, E., Tschuor, F., Reusch, C.E., 2009. First experiences with the continuous real-time glucose monitoring system (Guardian REAL-time CGMS) in a cat with Diabetes mellitus. Schweiz Arch Tierheilkd. 151, 27-30.

16. Nelson, R.W., Henley, K., Cole, C., Pzir clinical study group, 2009. Field safety and efficacy of protamine zinc recombinant human insulin for treatment of diabetes mellitus in cats. J Vet Intern Med. 23, 787-793.

492 17. Norsworthy, G., Lynn, R., Cole, C., 2009. Preliminary study of 493 protamine zinc recombinant insulin for the treatment of diabetes mellitus in cats. Vet Ther. 10, 24-28. 
495 18. Rand, J. and Gottlieb S.A., 2017. Feline diabetes mellitus, in:

496 Ettinger, S.T., Feldman E.C., Cote, E. (Eds.), Textbook of veterinary

497 internal medicine, eight ed. Saunders, Philadelphia, pp. 1781-1795.

498 19. Ristic, J.M., Herrtage, M.E., Walti-Lauger, S.M., Slater, L.A.,

499 Church, D.B., Davison, L.J., Catchpole, B., 2005. Evaluation of a

500 continuous glucose monitoring system in cats with diabetes mellitus.

$501 \quad$ J Feline Med Surg. 7, 153-162.

502 20. Rodbard, H.W., Cariou, B., Zinman, B., Handelsman, Y., Philis-

503 Tsimikas, A., Skojth, T.V., Rana, A., Methieu, C., BEGIN Once

504 Long trial investigators, 2013. Comparison of insulin degludec with

505 insulin glargine in insulin-naive subjects with Type 2 diabetes: a 2-

506 year randomized, treat-to-target trial. Diabet Med. 30, 1298-1304.

507 21. Siegmund, T., Kolassa, R., Thomas, A., 2011. Sensor-based therapy

508 and sensor-based pump therapy. Unimed Science, Bremen.

509 22. Smith, J.R., Vrono, Z., Rappoport, G.S., Turek, M.M., Creevy, K.E.,

510 2012. A survey of southeastern United States veterinarians`

511 preferences for managing cats with diabetes mellitus. J Feline Med

$512 \quad$ Surg. 14(10), 716-722.

513 23. Surman, S., Fleeman, L., 2013. Continuous glucose monitoring in

$514 \quad$ small animals. Vet Clin North Am Small Anim Pract. 43, 381-406.

515 24. Ward, C., Louviere, A., 2015. Efficacy of ProZinc insulin in naive

516 and insulin-established cats using continuous interstitial glucose

517 monitoring. 2015 ACVIM Forum Research Abstract Program. J Vet

$518 \quad$ Intern Med. 29(4), 1171-1172. 
519 25. Zini, E., Moretti, S., Tschuor, F., Reusch, C.E., 2009. Evaluation of 520 a new portable glucose meter designed for the use in cats. Schweiz $521 \quad$ Arch Tierheilkd. 151, 448-451.

522 26. Zinman, B., Fulcher, G., Rao, P.V., Thomas, N., Endahl, L.A., 523 Johansen, T., Lindh, R., Lewin, A., Rosenstock, J., Pinget, M., 524 Mathieu, C., 2011. Insulin degludec, an ultra-long-acting basal 525 insulin, once a day or three times a week versus insulin glargine 526 once a day in patients with type 2 diabetes: a 16-week, randomised, 527 open-label, phase 2 trial. Lancet. 377, 924-931. 